\title{
Síndrome de May-Thurner
}

\author{
Navarro TP. ${ }^{1}$, Castro-Bernardes R. ${ }^{1}$ \\ ${ }^{1}$ Procópio RJ, Belo Horizonte - Brasil. \\ E-mail: túlio.navarro@gamil.com
}

Navarro, T.P.; Castro-Bernardes, R. 2013. Síndrome de May-Thurner, p.74. In: Bastos, Francisco Reis. Anais do V Simpósio Internacional de Flebologia [Blucher Medical Proceedings n.1 v.1]. São Paulo: Blucher, 2014 http://dx.doi.org/10.5151/medpro-flebo-SIF_47
Trata-se de sinais e sintomas decorrentes da compressão da veia ilíaca comum esquerda ou veia cava inferior pela artéria ilíaca comum direita, que com insuficiência venosa crônica como edema e alterações tróficas e/ ou trombose venosa profunda no membro inferior esquerdo. Descrita em 1956 por May e Thurner a partir de autópsias. Cockett e Thomas em 1965 descreveram série de 35 pacientes nos quais foram achados hiperplasia intimal na veia ilíaca. Pode lançar mão de métodos objetivos como: ecocolordoppler, flebografia Ilíaca (femoral) ou ultra som intravascular.

Os pacientes sintomáticos são os que mais se beneficiam, uma vez que medidas conservadoras são insuficientes para alívio dos sintomas. Nos pacientes assintomáticos a indicação é questionável na literatura.

Angioplastia venosa com stent se tornou o tratamento de escolha devido a baixa morbidade, praticamente sem mortalidade, com altas taxas de perviedade longo prazo e baixas taxas de re-estenose. Substituiu a cirurgia como primeira escolha. Angioplastia venosa é diferente de arterial, pois é sempre necessário uso de stent, que devem ser super dimencionados re-dilatados após sua liberação para evitar migração.

\section{Complicações}

No sítio de punção pode ocorrer desconforto, hematoma ou hematoma retroperitoneal. Trombose venosa profunda em $1 \%$ devido a extensão do stent para a veia contralateral e cava inferior. Reestenose intra-stent ocorre em 5\% em longo prazo.

Palavras-chave: Síndrome de May-Thurner, stent, veia ilíaca, compressão venosa. 